\title{
Type of kindergarten and other potential determinants of overweight in pre-school children
}

\author{
$\mathrm{K}_{\text {Rapp }}{ }^{1, *}, \mathrm{KH}$ Schick$^{2}, \mathrm{H}_{\text {Bode }}^{3}$ and SK Weiland ${ }^{1}$ \\ 'Department of Epidemiology, University of Ulm, Helmholtzstraße 22, D-8908 1 Ulm, Germany: ${ }^{2}$ Public Health \\ Office, Department of Paediatrics, Stuttgart, Germany: ${ }^{3}$ Department of Paediatrics, University of Ulm, Ulm, Germany
}

Submitted 9 August 2004: Accepted 25 January 2005

\begin{abstract}
Objective: The study aimed to assess the relationship of various types of kindergarten differing in length of care and food availability with the development of overweight in pre-school children.

Design, setting and subjects: A cross-sectional study was carried out in 2002 in Stuttgart, Germany, as part of the school entrance examination. Height and weight of 2140 children (participation 70.2\%) were measured and information on type of kindergarten and other potential determinants of overweight was collected by a parental questionnaire. Change in relative body mass index (BMI) position between the ages of 4 and 6 years was assessed using medical records.

Results: The prevalence of overweight or change in relative BMI position did not differ according to the type of kindergarten. For the prevalence of overweight in German children, adjusted odds ratios (OR) comparing institutions that open only in the morning with those opening in the morning and afternoon or for the full day were 0.86 (95\% confidence interval (CI) $0.40,1.83$ ) and 0.63 (95\% CI $0.25,1.58$ ), respectively. Parental BMI and duration of television watching were positively associated, and maternal educational status and duration of breast-feeding were negatively associated, with overweight and/or change in relative BMI position. The prevalence of overweight was substantially higher among non-German than among German children (adjusted OR 2.17 (95\% CI 1.53, 3.07)).

Conclusions: These data show no association between different types of kindergarten and the development of overweight in early childhood. Duration of television watching and breast-feeding, as well as the relatively high prevalence of overweight in ethnic minorities, deserve further attention.
\end{abstract}

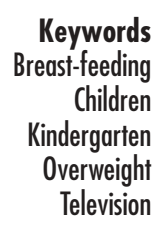

In industrialised countries, the prevalence of overweight among children has increased within the past two or three decades $^{1-3}$. While strong genetic determinants of overweight have been identified ${ }^{4,5}$, increases observed in the prevalence of overweight over such a short period of time can only be explained by changes of lifestyle or environmental factors. To date, the influence of nutritional factors is not fully understood ${ }^{6}$. However, besides energy intake, food intake has many other functions including psychological aspects, e.g. the compensation of frustration or boredom ${ }^{7}$. Especially in periods of negative emotions like anger, tension or fear there is an increased tendency to cope with these emotions through eating ${ }^{8}$. Emotional distress is associated with a higher intake of snacks in overweight subjects than in normal-weight subjects? These coping mechanisms are influenced by social settings and daily life conditions. A major determinant of the daily life of almost all children between the ages of 3 and 6 years in Germany is the institutional care in a kindergarten. In Germany, there are different types of kindergarten that differ in length of daily care, ranging from 4 to $10 \mathrm{~h}$ per day, and the availability of lunch and other foods. The objective of our cross-sectional study was to investigate whether these differences in institutional care affect the development of childhood overweight.

\section{Methods}

A random sample of 2140 6-year-old children (response rate $70.2 \%$ ) participated in the study, which was integrated in 2002 in the compulsory school entrance examination in Stuttgart, Germany. The parents were asked to complete and return a questionnaire and to bring the documentation of previous screening examinations ('Gelbes Buch', a standardised screening examination book). A questionnaire was also sent to the kindergartens to enquire about meals and food accessibility. The study was approved by the ethics committee of the University of Ulm. 


\section{Measurements of beight and weight}

At the school entrance examination, medical personnel routinely measure children's height and weight. The data were abstracted for the study. As proposed by the European Childhood Obesity Group ${ }^{10}$, overweight/obesity was defined as a body mass index (BMI) greater than the 90th/97th percentile. National age- and sex-specific BMI curves served as reference charts ${ }^{11}$. For external comparability we further calculated overweight and obesity by the international cut-off points suggested by Cole et $a l^{12}$.

Additional information was extracted from the children's screening books: weeks of gestation and weight at delivery, as well as height and weight measured at the age of 4 years (U8). The screening examination 'U8' takes place in a paediatrician's practice and the data are recorded by medical staff. The screening examination is free of charge for all children; therefore the participation rate is high. On the basis of these records the BMI at the age of 4 years could also be calculated for 1817 (84.9\%) of the participating children. With the exception of ethnicity we found no evidence for significant selection bias in this subgroup of children. With the data from two examinations ('U8' and school entrance examination) we were able to make a longitudinal assessment between the age of 4 and 6 years.

\section{Questionnaire}

The questionnaire was completed by the parents. We asked about the child's age, sex, country of birth, mother tongue and type of kindergarten. In Germany four types of kindergarten are usually offered:

1. morning ( 08.00 to 12.00 hours, lunch at home);

2. morning and afternoon (08.00 to 12.00 hours and 14.00 to 16.00 hours, lunch at home);

3. morning-early afternoon (08.00 to 13.30 hours, snack at about noon, no warm lunch in the kindergarten);

4. full-time (care up to $10 \mathrm{~h}$ daily, warm lunch in the kindergarten).

Additional questions asked about other potential determinants of overweight. These included questions on average daily duration of television watching or computer playing; height and weight of father and mother; maternal smoking during pregnancy; duration of exclusive breast-feeding (without addition of juice or solid food); and maternal educational status (assessed by years of school education: low, $\leq 9$ years; medium, $>9$ years and $<13$ years; high, 13 years).

An additional short questionnaire was developed for kindergarten staff members to investigate differences between the types of kindergarten in availability of lunch and other foods (e.g. snacks offered by the kindergarten or brought from home). The questionnaire was sent to a random sub-sample of 46 kindergartens, representing all types of care. Thirty completed questionnaires were returned (response rate 65\%).

\section{Statistical analysis}

The association of the different variables with the prevalence of overweight (assessed by the national BMI curves) was expressed by crude and adjusted odds ratios (ORs) with 95\% confidence intervals (CIs). Adjusted ORs were calculated using multiple logistic regression models. In order to assess weight development it is necessary to calculate the difference of age-dependent body mass indices, because there are characteristic changes of BMI during childhood and adolescence ${ }^{13}$. The relative BMI position for each child in comparison to its respective age group at different points of time is of interest. The $\mathrm{SDS}_{\mathrm{LMS}}$ method was developed to allow calculation of standard deviation scores (SDS) even for not normally distributed variables ${ }^{11,14}: \quad \mathrm{SDS}_{\mathrm{LMS}}=\left[(\mathrm{BMI} / M(t)]^{L(t)}-1\right] /[L(t) S(t)]$, with median $M$, variation coefficient $S$ and the box-Cox power transformation $L$.

The difference (DIF) between the two standard deviation scores $\left(\mathrm{SDS}_{\mathrm{LMS}}\right)$ at the school entrance examination (SEE) and the screening examination at age 4 years (U8) describes the relative weight change for each child in comparison to the corresponding age group between the age of 4 and 6 years: $\operatorname{SDS}_{\mathrm{LMS}}(\mathrm{DIF})$ $=\mathrm{SDS}_{\mathrm{LMS}}(\mathrm{SEE})-\mathrm{SDS}_{\mathrm{LMS}}(\mathrm{U} 8)$. The $\mathrm{SDS}_{\mathrm{LMS}}(\mathrm{DIF})$ is normally distributed. Multiple linear regression models were used to determine the association of several variables of interest with the change in relative BMI position.

All multivariate models were performed as 'complete case analyses' and interactions were considered. The data were calculated stratified by mother tongue because a significant interaction $(P<0.05)$ between mother tongue and duration of breast-feeding on the risk of overweight was observed. In the following text, we refer to children with German mother tongue as 'children with German ethnicity' or as 'German children'. After backward selection, only variables with $P$-values of less than 0.1 remained in the final models. Sex was kept in all final multivariate models, because sex-specific differences of care in the kindergartens could not be excluded. All calculations were carried out with SAS version 8.2 software (SAS Institute, Cary, NC, USA).

\section{Results}

Table 1 presents the demographic, socio-economic and anthropometric characteristics of the study population. There were slightly more boys than girls, and $69 \%$ of the children had German as mother tongue. About 22\% of the children attended kindergarten in the morning hours only and $13 \%$ went to kindergarten both in the morning and in the afternoon, but had lunch at home. Forty-four per cent of the children went to a kindergarten that was open in the morning and during the early afternoon but did not offer lunch. Finally, $15 \%$ of the participants attended a kindergarten full time, i.e. these children also had lunch in the institution. 
Table 1 Demographic, socio-economic and anthropometric characteristics of the study population $(n=2140)$

\begin{tabular}{|c|c|c|c|c|}
\hline & \multicolumn{2}{|c|}{ German $(n=1476)$} & \multicolumn{2}{|c|}{ Non-German $(n=664)$} \\
\hline & Girls $(n=702)$ & Boys $(n=774)$ & Girls $(n=313)$ & Boys $(n=351)$ \\
\hline \multicolumn{5}{|l|}{ Measurement at school entrance examination } \\
\hline Age (years) & $6.1(0.3)^{\star} \dagger$ & $6.2(0.4)$ & $6.2(0.3)$ & $6.2(0.3)$ \\
\hline $\mathrm{BMI}\left(\mathrm{kg} \mathrm{m}^{-2}\right)$ & $15.47(1.68)^{*}$ & $15.62(1.66)^{*}$ & $16.42(2.25)$ & $16.65(2.35)$ \\
\hline \multicolumn{5}{|l|}{ Overweight (\%) } \\
\hline$\geq 90$ th percentile & $8.03^{*}$ & $7.00^{*}$ & 20.83 & 23.43 \\
\hline International cut-off point & $11.91^{*}$ & $8.43^{*}$ & 31.09 & 26.57 \\
\hline \multicolumn{5}{|l|}{ Obesity (\%) } \\
\hline$\geq 97$ th percentile & $2.87^{*}$ & $2.46^{\star}$ & 8.65 & 9.71 \\
\hline \multirow{2}{*}{\multicolumn{5}{|c|}{ Type of kindergarten }} \\
\hline & & & & \\
\hline Morning only (\%) & 25.44 & 24.27 & 17.91 & 14.81 \\
\hline Morning and afternoon, lunch at home (\%) & 9.50 & 14.06 & 14.18 & 13.47 \\
\hline Morning-early afternoon, snack instead of lunch (\%) & 48.10 & 42.57 & 38.43 & 43.10 \\
\hline Full-time, lunch in the kindergarten (\%) & 11.26 & 12.47 & 21.64 & 23.57 \\
\hline Any other (\%) & 5.70 & 6.64 & 7.83 & 5.05 \\
\hline Birth weight & $\dagger$ & & $\dagger$ & \\
\hline$<2500 \mathrm{~g}(\%)$ & 5.15 & 6.67 & 3.61 & 6.43 \\
\hline $2500-3999 \mathrm{~g}(\%)$ & 86.84 & 80.39 & 89.84 & 80.99 \\
\hline$\geq 4000 \mathrm{~g}(\%)$ & 8.01 & 12.94 & 6.56 & 12.57 \\
\hline \multicolumn{5}{|l|}{ Maternal smoking during pregnancy } \\
\hline No $(\%)$ & 85.18 & 85.90 & 87.74 & 83.53 \\
\hline Yes (\%) & 14.82 & 14.10 & 12.26 & 16.47 \\
\hline \multicolumn{5}{|l|}{ Exclusive breast-feeding duration } \\
\hline$<2$ months $(\%)$ & 26.13 & 26.84 & 32.63 & 33.95 \\
\hline $2-4$ months $(\%)$ & 21.46 & 24.17 & 27.37 & 28.09 \\
\hline $5-6$ months (\%) & 35.77 & 32.84 & 19.65 & 19.75 \\
\hline$>6$ months $(\%)$ & 16.64 & 16.15 & 20.35 & 18.21 \\
\hline \multicolumn{5}{|l|}{ Maternal educational status } \\
\hline Low (\%) & 15.41 & 17.17 & 54.93 & 50.73 \\
\hline Medium (\%) & 36.05 & 36.04 & 23.36 & 26.10 \\
\hline High (\%) & 48.55 & 46.79 & 21.71 & 23.17 \\
\hline Maternal BMI $\left(\mathrm{kg} \mathrm{m}^{-2}\right)$ & $22.50(3.49)^{*} \dagger$ & $22.93(3.81)^{\star}$ & $24.26(3.89)$ & $24.25(4.50)$ \\
\hline Paternal BMI $\left(\mathrm{kg} \mathrm{m}^{-2}\right)^{\prime}$ & $24.83(2.82)^{*} \dagger$ & $25.17(3.04)$ * & $26.48(3.33)$ & $26.03(3.16)$ \\
\hline Television/computer & ${ }^{*} \dagger$ & * & & \\
\hline$<1 \mathrm{~h}$ daily $(\%)$ & 71.35 & 65.31 & 24.68 & 25.59 \\
\hline $1-2 \mathrm{~h}$ daily (\%) & 25.76 & 30.88 & 60.06 & 55.59 \\
\hline$>2 \mathrm{~h}$ daily (\%) & 2.89 & 3.81 & 15.26 & 18.82 \\
\hline \multicolumn{5}{|l|}{ Measurement at the age of 4 years (U8) } \\
\hline Age (years) & $4.0(0.2)^{\star}$ & $4.0(0.2)$ & $3.9(0.2)$ & $4.0(0.2)$ \\
\hline $\mathrm{BMI}\left(\mathrm{kg} \mathrm{m}^{-2}\right)$ & $15.42(1.34)^{*} \dagger$ & $15.59(1.24)^{*}$ & $15.87(1.68)$ & $16.18(1.68)$ \\
\hline \multicolumn{5}{|l|}{ Overweight (\%) } \\
\hline$\geq 90$ th percentile & $7.52^{*}$ & $5.79^{*}$ & 13.10 & 16.02 \\
\hline International cut-off point & $9.28^{*} \dagger$ & $5.64^{*}$ & 15.72 & 15.63 \\
\hline \multicolumn{5}{|l|}{ Obesity $(\%)$} \\
\hline$\geq 97$ th percentile & $1.44^{\star}$ & $1.45^{\star}$ & 4.37 & 6.64 \\
\hline International cut-off point & $0.80^{*}$ & $0.72^{*}$ & 3.06 & 4.69 \\
\hline
\end{tabular}

BMI - body mass index.

Values are mean (standard deviation). Differences between groups were tested for continuous variables by $t$-tests, for categorical variables by chi-square tests.

${ }^{*} P<0.05$ for comparison between ethnicity (German girls vs. non-German girls and German boys vs. non-German boys).

$\dagger P<0.05$ for comparison between sex (German girls vs. German boys and non-German girls vs. non-German boys).

There was no statistically significant association between the prevalence of overweight at the age of 6 years and the type of kindergarten attended by the children (Table 2). Additional variables of interest that did show a significant positive association included maternal smoking during pregnancy (significant only in the bivariate analysis), maternal as well as paternal BMI, and duration of television watching/computer playing. Duration of breast-feeding and maternal educational status showed an inverse association. A similar pattern was observed for overweight at the age of 4 years (Table 3) with notable exceptions: the prevalence of overweight was positively associated with duration of breast-feeding (in German children) and with high birth weight (the latter only in the bivariate analyses).

Determinants of longitudinal change in relative BMI position are presented in Table 4. Again, the type of kindergarten did not show a statistically significant association. Other factors of interest, however, were found to have significant relationships. Among German children there were positive associations with paternal BMI and duration of television/computer watching. Duration of breast-feeding was inversely related. Among children with non-German ethnicity, duration of 
Table 2 Determinants of overweight ( $\geq 90$ th percentile) at the age of 6 years by ethnicity

\begin{tabular}{|c|c|c|c|c|}
\hline & \multicolumn{2}{|c|}{ German } & \multicolumn{2}{|c|}{ Non-German } \\
\hline & Crude OR $(95 \% \mathrm{Cl})$ & $\begin{array}{c}\text { Adjusted } \\
\mathrm{OR}^{*}(95 \% \mathrm{Cl})\end{array}$ & Crude OR $(95 \% \mathrm{Cl})$ & $\begin{array}{c}\text { Adjusted } \\
\mathrm{OR}^{*}(95 \% \mathrm{Cl})\end{array}$ \\
\hline \multicolumn{5}{|l|}{ Type of kindergarten } \\
\hline Morning only & 1.00 & 1.00 & 1.00 & 1.00 \\
\hline Morning and afternoon, lunch at home & $1.27(0.66,2.42)$ & $0.86(0.40,1.83)$ & $0.86(0.41,1.82)$ & $0.91(0.39,2.14)$ \\
\hline Morning-early afternoon, snack instead of lunch & $0.93(0.57,1.53)$ & $0.77(0.45,1.34)$ & $1.00(0.56,1.78)$ & $1.13(0.57,2.22)$ \\
\hline Full-time, lunch in the kindergarten & $1.27(0.66,2.42)$ & $0.63(0.25,1.58)$ & $1.06(0.55,2.01)$ & $0.76(0.33,1.71)$ \\
\hline \multicolumn{5}{|l|}{ Sex } \\
\hline Boy & 1.00 & 1.00 & 1.00 & 1.00 \\
\hline Girl & $1.08(0.73,1.60)$ & $1.31(0.82,2.08)$ & $0.83(0.57,1.21)$ & $0.85(0.52,1.39)$ \\
\hline \multicolumn{5}{|l|}{ Birth weight } \\
\hline$<2500 \mathrm{~g}$ & $0.76(0.30,1.93)$ & $\dagger$ & $0.81(0.33,2.02)$ & $\dagger$ \\
\hline $2500-3999 \mathrm{~g}$ & 1.00 & $\dagger$ & 1.00 & $\dagger$ \\
\hline$\geq 4000 \mathrm{~g}$ & $1.17(0.64,2.15)$ & $\dagger$ & $1.48(0.82,2.65)$ & $\dagger$ \\
\hline \multicolumn{5}{|l|}{ Maternal smoking during pregnancy } \\
\hline No & 1.00 & 1.00 & 1.00 & $\dagger$ \\
\hline Yes & $2.06(1.29,3.30)$ & $1.67(0.94,2.97)$ & $1.94(1.20,3.15)$ & $\dagger$ \\
\hline \multicolumn{5}{|l|}{ Exclusive breast-feeding duration } \\
\hline$<2$ months & 1.00 & $\dagger$ & 1.00 & 1.00 \\
\hline $2-4$ months & $0.77(0.45,1.34)$ & $\dagger$ & $0.82(0.51,1.33)$ & $0.50(0.28,0.92)$ \\
\hline $5-6$ months & $0.57(0.34,0.97)$ & $\dagger$ & $0.54(0.30,0.97)$ & $0.49(0.24,1.00)$ \\
\hline$>6$ months & $0.84(0.46,1.53)$ & $\dagger$ & $0.64(0.36,1.13)$ & $0.35(0.16,0.74)$ \\
\hline \multicolumn{5}{|l|}{ Maternal educational status } \\
\hline Low & 1.00 & 1.00 & 1.00 & $\dagger$ \\
\hline Medium & $0.63(0.38,1.04)$ & $0.88(0.47,1.63)$ & $0.54(0.33,0.88)$ & $\dagger$ \\
\hline High & $0.39(0.23,0.66)$ & $0.50(0.25,1.02)$ & $0.52(0.31,0.89)$ & $\dagger$ \\
\hline Maternal BMI & $1.11(1.06,1.16)$ & $1.08(1.03,1.14)$ & $1.09(1.05,1.14)$ & $1.08(1.02,1.15)$ \\
\hline Paternal BMI & $1.15(1.07,1.23)$ & $1.10(1.03,1.19)$ & $1.08(1.01,1.14)$ & $1.09(1.01,1.17)$ \\
\hline \multicolumn{5}{|l|}{ Television/computer } \\
\hline$<1 \mathrm{~h}$ daily & 1.00 & 1.00 & 1.00 & 1.00 \\
\hline $1-2 \mathrm{~h}$ daily & $1.89(1.23,2.91)$ & $1.11(0.65,1.91)$ & $2.16(1.27,3.66)$ & $2.40(1.17,4.91)$ \\
\hline$>2 \mathrm{~h}$ daily & $4.29(2.03,9.09)$ & $2.37(0.89,6.28)$ & $2.85(1.52,5.35)$ & $3.16(1.36,7.34)$ \\
\hline
\end{tabular}

OR - odds ratio; $\mathrm{Cl}$ - confidence interval, $\mathrm{BMI}$ - body mass index.

${ }^{*}$ All variables of the final multivariate model are listed.

† Not included in the final multivariate model.

Table 3 Determinants of overweight ( $\geq 90$ th percentile) at the age of 4 years by ethnicity

\begin{tabular}{|c|c|c|c|c|}
\hline & \multicolumn{2}{|c|}{ German } & \multicolumn{2}{|c|}{ Non-German } \\
\hline & Crude OR $(95 \% \mathrm{Cl})$ & $\begin{array}{c}\text { Adjusted } \\
\mathrm{OR}^{\star}(95 \% \mathrm{Cl})\end{array}$ & Crude OR $(95 \% \mathrm{Cl})$ & $\begin{array}{c}\text { Adjusted } \\
\mathrm{OR}^{*}(95 \% \mathrm{Cl})\end{array}$ \\
\hline \multicolumn{5}{|l|}{ Sex } \\
\hline Boy & 1.00 & 1.00 & 1.00 & 1.00 \\
\hline Girl & $1.35(0.82,2.23)$ & $1.52(0.91,2.54)$ & $0.84(0.50,1.40)$ & $0.79(0.47,1.33)$ \\
\hline \multicolumn{5}{|l|}{ Birth weight } \\
\hline$<2500 \mathrm{~g}$ & $0.41(0.10,1.71)$ & $\dagger$ & $1.29(0.43,3.92)$ & $\dagger$ \\
\hline $2500-3999 \mathrm{~g}$ & 1.00 & $\dagger$ & 1.00 & $\dagger$ \\
\hline$\geq 4000 \mathrm{~g}$ & $2.02(1.13,3.59)$ & $\dagger$ & $2.09(1.03,4.26)$ & $\dagger$ \\
\hline \multicolumn{5}{|c|}{ Maternal smoking during pregnancy } \\
\hline No & 1.00 & $\dagger$ & 1.00 & $\dagger$ \\
\hline Yes & $1.23(0.68,2.24)$ & $\dagger$ & $1.98(1.02,3.84)$ & $\dagger$ \\
\hline \multicolumn{5}{|c|}{ Exclusive breast-feeding duration } \\
\hline$<2$ months & 1.00 & 1.00 & 1.00 & $\dagger$ \\
\hline $2-4$ months & $2.74(1.24,6.07)$ & $3.36(1.49,7.59)$ & $1.01(0.53,1.92)$ & $\dagger$ \\
\hline $5-6$ months & $1.74(0.79,3.84)$ & $2.32(1.02,5.24)$ & $0.73(0.34,1.56)$ & $\dagger$ \\
\hline$>6$ months & $2.24(0.94,5.37)$ & $2.75(1.13,6.71)$ & $0.87(0.42,1.80)$ & $\dagger$ \\
\hline \multicolumn{5}{|c|}{ Maternal educational status } \\
\hline Low & 1.00 & $\dagger$ & 1.00 & 1.00 \\
\hline Medium & $0.59(0.32,1.06)$ & $\dagger$ & $0.39(0.19,0.78)$ & $0.38(0.19,0.77)$ \\
\hline High & $0.58(0.33,1.02)$ & $\dagger$ & $0.42(0.20,0.86)$ & $0.41(0.20,0.85)$ \\
\hline Maternal BMI & $1.08(1.02,1.14)$ & $1.09(1.02,1.16)$ & $1.02(0.96,1.08)$ & $\dagger$ \\
\hline Paternal BMI & $1.13(1.05,1.22)$ & $1.13(1.04,1.22)$ & $1.06(0.98,1.15)$ & $t$ \\
\hline
\end{tabular}

OR - odds ratio; $\mathrm{Cl}$ - confidence interval; $\mathrm{BMI}$ - body mass index.

${ }^{*}$ All variables of the final multivariate model are listed.

† Not included in the final multivariate model. 


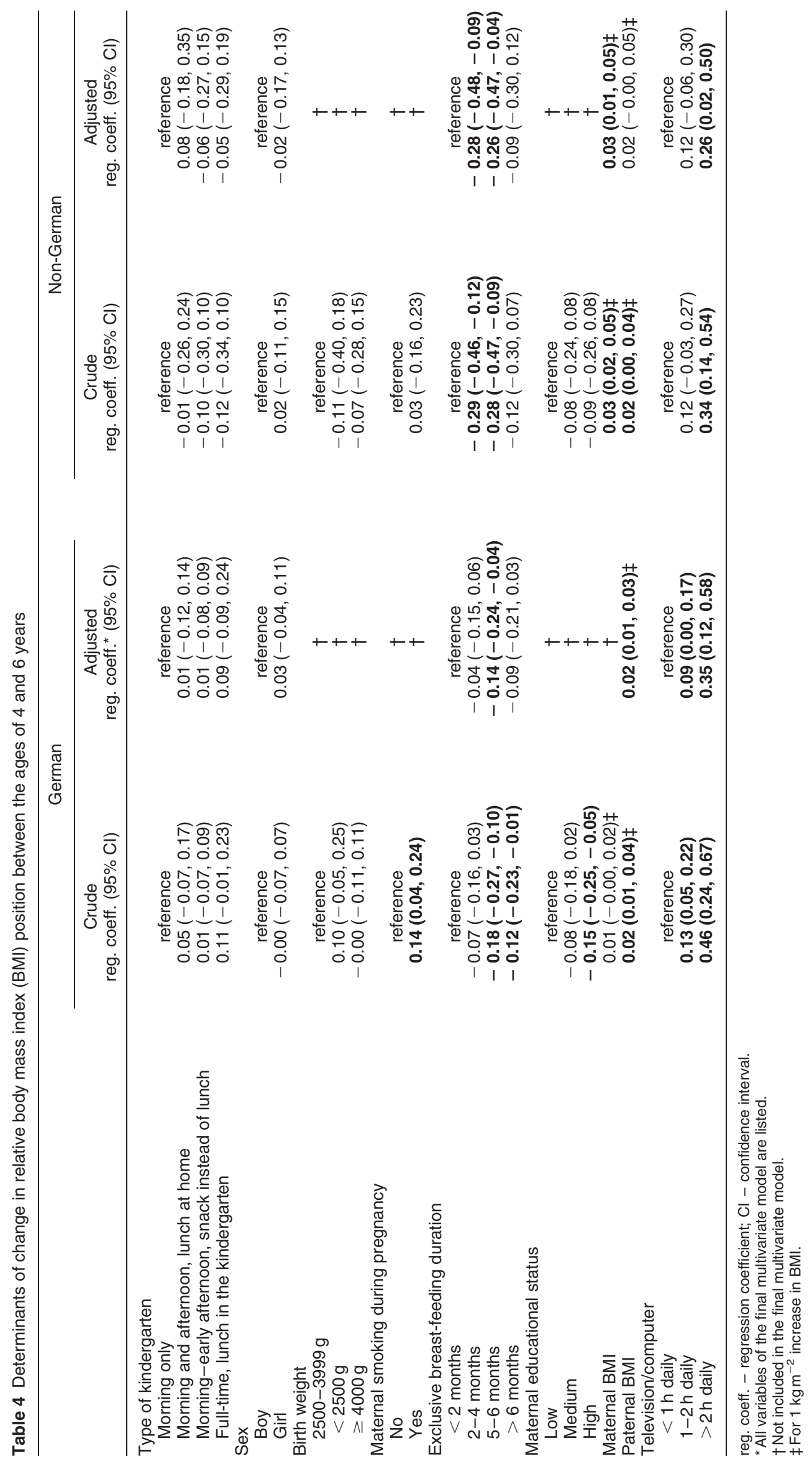


breast-feeding, maternal BMI and duration of television/ computer use remained significant in the final multivariate model.

Non-German children had a substantially higher prevalence of overweight and obesity than German children, regardless of age, sex or use of national ${ }^{11}$ or international $^{12}$ cut-off points (Table 1 ). This effect was reduced but remained strong and statistically significant after adjustment for the above-mentioned variables (Table 5). The adjusted OR for the association with the prevalence of overweight at age 4 and 6 years was 1.94 (95\% CI 1.28, 2.94) and 2.24 (95\% CI 1.51, 3.27), respectively. Also, the increase in relative BMI position was much higher in children with non-German ethnicity (adjusted regression coefficient $0.10 ; 95 \%$ CI $0.02,0.18$ ) in comparison with their German peers.

\section{Discussion}

A considerable part of eating behaviour is the consequence of learning processes ${ }^{15}$. The hypothesis on which our examination was based was developed on this premise. We assumed that children who have regular meals over the whole day, possibly best realised in a kindergarten with full-time care, have less access to snacks and other food between meals than children who attend kindergarten mostly in the morning without having lunch in the institution and without an institutional regulation of food access in the afternoon. Therefore children in a kindergarten with full-time care should have less possibility to compensate situations of uneasiness like annoyance, frustration or boredom with the intake of food. We expected a lower prevalence of overweight in

Table 5 Effect of ethnicity on being overweight ( $\geq 90$ th percentile) at the age of 4 years and 6 years (cross-sectional examinations) and on change of relative body mass index (BMI) position between the ages of 4 and 6 years (longitudinal investigation)

\begin{tabular}{|c|c|c|}
\hline & German & Non-German \\
\hline \multicolumn{3}{|l|}{ Being overweight } \\
\hline \multicolumn{3}{|l|}{ Age: 4 years } \\
\hline Crude OR $(95 \% \mathrm{Cl})$ & 1.00 & $2.42(1.74,3.38)$ \\
\hline Adjusted OR $(95 \% \mathrm{Cl})$ & 1.00 & $1.94(1.28,2.94)^{*}$ \\
\hline \multicolumn{3}{|l|}{ Age: 6 years } \\
\hline Crude OR $(95 \% \mathrm{Cl})$ & 1.00 & $3.52(2.70,4.60)$ \\
\hline Adjusted OR $(95 \% \mathrm{Cl})$ & 1.00 & $2.24(1.51,3.27) \dagger$ \\
\hline \multicolumn{3}{|l|}{ Change of relative BMI position } \\
\hline Crude reg. coeff. $(95 \% \mathrm{Cl})$ & reference & $0.22(0.15,0.28)$ \\
\hline Adjusted reg. coeff. ( $95 \% \mathrm{Cl})$ & reference & $0.10(0.02,0.18) \ddagger$ \\
\hline
\end{tabular}

OR - odds ratio; $\mathrm{Cl}$ - confidence interval; reg. coeff. - regression coefficient

*Adjusted for sex, exclusive breast-feeding duration (dichotomous variable: $<2$ months/>2 months), maternal BMI, paternal BMI, maternal educational status.

† Adjusted for sex, exclusive breast-feeding duration (dichotomous variable: $<2$ months/ $>2$ months), maternal BMI, paternal BMI, maternal educational status, daily television/computer time.

$\ddagger$ Adjusted for sex, exclusive breast-feeding duration (dichotomous variable: $<2$ months/>2 months), maternal BMI, paternal BMI, daily television/computer time. children attending a full-time kindergarten that offers up to $10 \mathrm{~h}$ of care (with regular meals over the whole day) compared with children with kindergarten care for a maximum of $4 \mathrm{~h}$ per day. To our knowledge, this question has not yet been investigated.

The results of this study, however, do not support this hypothesis. There were no statistically significant differences in the prevalence of overweight depending on the kindergarten. The group of children attending kindergarten full-time had neither a difference in the prevalence of overweight at age 6 years nor a longitudinal change of relative BMI position over time. However, our study had methodological limitations, which should be considered when interpreting the results. An obvious limitation is the sample size. Although our investigation comprised more than 2000 children, the numbers in the different categories of kindergarten were much smaller and we may have missed effects due to low numbers. For example, given the observed prevalence of overweight in our study population, a sample size of 176 children in each group would be needed to detect a twofold difference with $\alpha=0.05$ and power of $80 \%$. In addition, access to food at home outside kindergarten hours could not be taken into account. A further limitation may have been that our categories of day-care type of kindergarten, based on parental reports, did not discriminate well enough between eating patterns and food accessibility. Nevertheless, an additional questionnaire that was sent to participating kindergartens showed that most kindergartens $(83 \%)$ have a clear rule that foods like sweets and drinks are not allowed to be brought from home. In addition, none of the responding kindergartens offered free access to sweets or biscuits during the day. Free access to fruits or vegetables, in turn, was more frequent in kindergartens with full-time care (nine out of 13 kindergartens) than in kindergartens with less hours of daily care (three out of 17 kindergartens). As expected, nearly all kindergartens with full-time care (12 of 13) offered lunch. Thus, the duration of daily care can be assumed to be a surrogate measure for a period of structured and limited access to food, particularly to sweets.

A strength of our study was that we had measurements of height and weight both at age 6 and at 4 years, which allowed us to investigate risk factors which operate in early childhood, like type of kindergarten. Furthermore, we could consider a number of potential confounders, including parental BMI. As in previous studies, we found that BMI of the parents is an important determinant of overweight or weight gain ${ }^{16-18}$.

Similar to recent investigations of 6-year-old German children ${ }^{19,20}$, maternal smoking during pregnancy was found to increase the risk of overweight in childhood (adjusted OR not significant, but of the same size as in the cited investigations ${ }^{19,20}$ ). It has been speculated that in utero exposure to nicotine may lead to alterations in 
the neurotransmitter system of the brain and persistent deficits in impulse control. Maternal dietary habits associated with smoking, such as poor diet or the prevention of excessive weight gain during pregnancy, may also be a contributing factor. For example, data from the Dutch famine study ${ }^{21}$ showed a higher prevalence of obesity in recruits whose nutrition in utero was deprived in the first half of pregnancy.

An association between the daily duration of television watching and the prevalence of overweight has been reported in several cross-sectional investigations ${ }^{22-24}$. Our data on television watching and computer playing were based on parental reports at the child's age of 6 years. However, it is likely that the information provided relates not to one point of time but to a longer period. Therefore, we assume that our analysis is likely to show a causal association between television watching/computer playing and an increase of the relative BMI position between the ages of 4 and 6 years.

The influence of the duration of breast-feeding has been investigated in several studies ${ }^{25}$. The results are conflicting. In our study breast-feeding showed a protective effect in 6-year-olds, although after adjustment for potential confounding factors the associations remained statistically significant only in non-German children. In 4-year-old German children, however, longer periods of breastfeeding were associated with a higher prevalence of overweight. This is an unexpected finding that cannot readily be explained. In our longitudinal comparison, however, a longer duration of breast-feeding was associated with a decrease in relative BMI position. The fact that this was seen in children of both German and non-German ethnicity argues against the view that the longitudinal effect may be simply due to 'catch-up growth' among German children who had been breast-fed for less than 2 months. The fact that the impact of breast-feeding was not seen before the age of 4 years is surprising, but consistent with the results of a prospective German investigation $^{26}$. Bergmann et al. reported that a protective effect of breast-feeding did not become apparent before the age of 4 years. This may explain why an inverse association between breast-feeding and overweight was more likely in investigations which examined older children ( $\geq 6$ years) than in those studying younger children $^{25-31}$. As a causal protective effect of breastfeeding, several mechanisms are discussed ${ }^{26}$. Our results suggest a long-lasting mechanism where the effect does not manifest itself until several years have passed. However, these results do not allow us to attribute the effect to either certain ingredients in breast milk or an early learning process of self-controlled food intake.

In the USA differences in the prevalence of overweight between children of differing ethnicity were described ${ }^{32}$. For children living in Germany, it was recently shown for the first time in a large sample that the whole BMI distribution in non-German children compared with
German children has shifted towards higher values ${ }^{3}$. In Germany children with non-German ethnicity come mainly from Mediterranean countries (e.g. Turkey, Italy, former Yugoslavia). Our data confirm a much higher prevalence of overweight in non-German children. Their parents, compared with the parents of German children, had also a higher mean BMI. Whether and to what extent this difference in the prevalence of overweight is due to genetic factors are not clear. For children in Germany we were able to examine the ethnic influence on the prevalence of overweight in multivariate models for the first time. These allowed adjustment for the parent's BMI and considered, besides others, a genetic component. But even after adjustment, the risk of overweight or weight gain was significantly higher in non-German children. Possible reasons for their higher prevalence of overweight could be factors like decreased physical activity or different consumption behaviour compared with German children. In our investigation, non-German children watched more television and their mothers were of lower educational status. These two variables diminished the crude regression coefficient of ethnicity strongly and thus explain part of the ethnic difference. As a consequence of the high prevalence of overweight in children of non-German ethnicity, an increase of obesityrelated diseases can be expected in this group in the future.

Our data were collected in the course of the compulsory health examination at school entrance. The participation rate was $70.2 \%$. It can therefore be assumed to be representative for 6-year old children of a German urban region with a high proportion of non-German children (31\%). The quality of the data both from the screening examination at the age of 4 years and the school entrance health examination at the age of 6 years should be valid, as the measurements at both examination dates were carried out and registered by medical staff. For variables derived from the questionnaire, preferential reporting cannot be ruled out. Overall, however, only a small part of the variance in the change of relative BMI position could be explained by the applied determinants $\left(R^{2}=0.04\right.$ and 0.08). A possible reason could be seen in the fact that physical activity and food intake were not taken into account.

The mother's emotional attitude towards her child is doubtless a fundamental factor of general development during childhood. It can be assumed that the psychological state of a child, which influences its eating habits, has consequences on its weight development. It is difficult to operationalise such a variable as 'emotional care'. One cannot exclude that the duration of breast-feeding and maternal smoking during pregnancy are only surrogate parameters of the variable 'emotional care'. In this case, a causal association between the duration of breast-feeding or maternal smoking during pregnancy and overweight later in life would be uncertain. 


\section{Conclusion}

Our investigation confirms the development of overweight in children as being of multi-factorial origin. Some of the determinants associated with weight gain, such as duration of television watching and computer playing, duration of breast-feeding, maternal smoking during pregnancy and mother's educational status, are potentially preventable. Different types of kindergarten did not have any influence on weight development. The high prevalence of overweight in non-German children requires additional preventive efforts in this subgroup.

\section{References}

1 Troiano RP, Flegal KM, Kuczmarski RJ, Campbell SM, Johnson CL. Overweight prevalence and trends for children and adolescents. The National Health and Nutrition Examination Surveys, 1963 to 1991. Archives of Pediatrics E Adolescent Medicine 1995; 149(10): 1085-91.

2 Freedman DS, Srinivasan SR, Valdez RA, Williamson DF, Berenson GS. Secular increases in relative weight and adiposity among children over two decades: the Bogalusa Heart Study. Pediatrics 1997; 99(3): 420-6.

3 Kalies H, Lenz J, von Kries R. Prevalence of overweight and obesity and trends in body mass index in German pre-school children, 1982-1997. International Journal of Obesity and Related Metabolic Disorders 2002; 26(9): 1211-7.

4 Stunkard AJ, Harris JR, Pedersen NL, McClearn GE. The body-mass index of twins who have been reared apart. New England Journal of Medicine 1990; 322(21): 1483-7.

5 Stunkard AJ, Sorensen TI, Hanis C, Teasdale TW, Chakraborty R, Schull WJ, et al. An adoption study of human obesity. New England Journal of Medicine 1986; 314(4): $193-8$.

6 Livingstone B. Epidemiology of childhood obesity in Europe. European Journal of Pediatrics 2000; 159(Suppl. 1): S14-34.

7 Canetti L, Bachar E, Berry EM. Food and emotion. Behavioural Processes 2002; 60(2): 157-64.

8 Macht M, Simons G. Emotions and eating in everyday life. Appetite 2000; 35(1): 65-71.

9 Lowe MR, Fisher EB Jr. Emotional reactivity, emotional eating, and obesity: a naturalistic study. Journal of Behavioral Medicine 1983; 6(2): 135-49.

10 Poskitt EM. Defining childhood obesity: the relative body mass index (BMI). European Childhood Obesity Group. Acta Paediatrica 1995; 84(8): 961-3.

11 Kromeyer-Hauschild K, Wabitsch M, Kunze D, Geller F, Geiss HC, Hesse V, et al. Perzentile für den Body-Mass-Index für das Kindes- und Jugendalter unter Heranziehung verschiedener deutscher Stichproben. Monatsschrift für Kinderheilkunde 2001; 149: 807-18.

12 Cole TJ, Bellizzi MC, Flegal KM, Dietz WH. Establishing a standard definition for child overweight and obesity worldwide: international survey. British Medical Journal 2000; 320(7244): 1240-3.

13 Rolland-Cachera MF, Deheeger M, Bellisle F, Sempe M, Guilloud-Bataille M, Patois E. Adiposity rebound in children: a simple indicator for predicting obesity. American Journal of Clinical Nutrition 1984; 39(1): 129-35.

14 Cole TJ. The LMS method for constructing normalized growth standards. European Journal of Clinical Nutrition 1990; 44(1): 45-60.
15 Koivisto Hursti UK. Factors influencing children's food choice. Annals of Medicine 1999; 31(Suppl. 1): 26-32.

16 Duran-Tauleria E, Rona RJ, Chinn S. Factors associated with weight for height and skinfold thickness in British children. Journal of Epidemiology and Community Health 1995; 49(5): 466-73.

17 Maffeis C, Talamini G, Tato L. Influence of diet, physical activity and parents' obesity on children's adiposity: a fouryear longitudinal study. International Journal of Obesity and Related Metabolic Disorders 1998; 22(8): 758-64.

18 Goran MI, Shewchuk R, Gower BA, Nagy TR, Carpenter WH, Johnson RK. Longitudinal changes in fatness in white children: no effect of childhood energy expenditure. American Journal of Clinical Nutrition 1998; 67(2): 309-16.

19 von Kries R, Koletzko B, Sauerwald T, von Mutius E, Barnert $\mathrm{D}$, Grunert $\mathrm{V}$, et al. Breast feeding and obesity: cross sectional study. British Medical Journal 1999; 319(7203): $147-50$.

20 von Kries R, Toschke AM, Koletzko B, Slikker W Jr. Maternal smoking during pregnancy and childhood obesity. American Journal of Epidemiology 2002; 156(10): 954-61.

21 Ravelli GP, Stein ZA, Susser MW. Obesity in young men after famine exposure in utero and early infancy. New England Journal of Medicine 1976; 295(7): 349-53.

22 Andersen RE, Crespo CJ, Bartlett SJ, Cheskin LJ, Pratt M. Relationship of physical activity and television watching with body weight and level of fatness among children: results from the Third National Health and Nutrition Examination Survey. Journal of the American Medical Association 1998; 279(12): 938-42.

23 Müller MJ, Koertringer I, Mast M, Langnase K, Grund A. Physical activity and diet in 5 to 7 years old children. Public Health Nutrition 1999; 2(3A): 443-4.

24 Robinson TN. Television viewing and childhood obesity. Pediatric Clinics of North America 2001; 48(4): 1017-25.

25 Butte NF. The role of breastfeeding in obesity. Pediatric Clinics of North America 2001; 48(1): 189-98.

26 Bergmann KE, Bergmann RL, Von Kries R, Bohm O, Richter R, Dudenhausen JW, et al. Early determinants of childhood overweight and adiposity in a birth cohort study: role of breast-feeding. International Journal of Obesity and Related Metabolic Disorders 2003; 27(2): 162-72.

27 Wilson AC, Forsyth JS, Greene SA, Irvine L, Hau C, Howie PW. Relation of infant diet to childhood health: seven year follow up of cohort of children in Dundee infant feeding study. British Medical Journal 1998; 316(7124): 21-5.

28 Gillman MW, Rifas-Shiman SL, Camargo CA Jr, Berkey CS, Frazier AL, Rockett HR, et al. Risk of overweight among adolescents who were breastfed as infants. Journal of the American Medical Association 2001; 285(19): 2461-7.

29 Hediger ML, Overpeck MD, Kuczmarski RJ, Ruan WJ. Association between infant breastfeeding and overweight in young children. Journal of the American Medical Association 2001; 285(19): 2453-60.

30 Liese AD, Hirsch T, von Mutius E, Keil U, Leupold W, Weiland SK. Inverse association of overweight and breast feeding in 9 to 10-y-old children in Germany. International Journal of Obesity and Related Metabolic Disorders 2001; 25(11): 1644-50.

31 Toschke AM, Vignerova J, Lhotska L, Osancova K, Koletzko B, Von Kries R. Overweight and obesity in 6- to 14-year-old Czech children in 1991: protective effect of breast-feeding. Journal of Pediatrics 2002; 141(6): 764-9.

32 Strauss RS, Pollack HA. Epidemic increase in childhood overweight, 1986-1998. Journal of the American Medical Association 2001; 286(22): 2845-8. 